Ensino, Saúde e Ambiente-V5 (2), pp. 258-269, ago. 2012

\title{
CORPO E GÊNERO: CONCEPÇÕES DE JOVENS SOBRE A INICIAÇÃO SEXUAL E PREVENÇÃO NO ENSINO DAS DOENÇAS SEXUALMENTE TRANSMISSÍVEIS
}

\author{
BODY AND GENDER: CONCEPTIONS OF YOUNG ON SEXUAL \\ INITIATION AND PREVENTION IN EDUCATION OF SEXUALLY \\ TRANSMITTED DISEASES \\ Roberta Ribeiro De Cicco ${ }^{1}$, Eliane Portes $\operatorname{Vargas}^{2}$ \\ ${ }^{1}$ Fundação Oswaldo Cruz /Instituto Oswaldo Cruz /PGEBS, robertarcicco@ gmail.com \\ ${ }^{2}$ Fundação Oswaldo Cruz /Instituto Oswaldo Cruz/LEAS, epvargas@ioc.fiocruz.br
}

\begin{abstract}
RESUMO
A adolescência, uma etapa fundamental do desenvolvimento infanto-juvenil pela qual passam os escolares, é caracterizada como um momento de transição, onde ocorrem mudanças de atitudes, questionamentos, opiniões e a passagem à sexualidade com o parceiro. Nesta fase, o corpo torna-se carregado de conotações ligados à apresentação e aos cuidados de si, sendo interpretado de formas bastante específicas pelas diferentes sociedades e grupos sociais. O estudo busca compreender as concepções de jovens escolares entre 17 e 20 anos de uma turma de $2^{\circ}$ ano do ensino médio de uma Escola Estadual da Região Metropolitana do RJ acerca da iniciação sexual e da prevenção das DSTs. Os resultados apontam concepções distintas de gênero quanto às decisões voltadas à iniciação sexual, bem como os cuidados relativos com o corpo frente ao reconhecimento dos sinais corporais e às atitudes de prevenção às DSTs.
\end{abstract}

Palavras-chave: Gênero, Corpo, Sexualidade, Jovens, DSTs.

\begin{abstract}
Adolescence, a fundamental step in the development of children and youth which they pass by the school, is characterized as a time of transition, where there are changes in attitudes, questions, opinions and the passage of sexuality with their partner. At this stage the body becomes charged with connotations related to the presentation and care of itself, be interpreted in very specific ways by different societies and social groups. The study seeks to understand the concepts of school youths between 17 and 20 years for a class of 2nd year of high school in a State School in the Metropolitan Region of Rio de Janeiro sexual initiation and prevention of STDs. The results suggest different conceptions of gender with regard to decisions aimed at sexual initiation as well as care for the body forward with the recognition of bodily signs and attitudes of preventing STIs.
\end{abstract}

Key words: Gender, Body, Sexualitiy, Youth, STDs.

\section{INTRODUÇÃO}

O presente trabalho discute as concepções de jovens escolares sobre sexualidade e corpo relacionadas ao tema das DSTs. Apoiado na perspectiva socioantropológica, o estudo possibilita compreender a sexualidade como uma construção social, ou seja, como construída de formas distintas através das culturas e do tempo (PARKER, 2010; LOURO, 2010) e argumenta que esta temática apresenta uma 
relevante interface entre a biologia e os aspectos subjetivos, de todo modo, socioculturais (BRETAS; SILVA, 2005) que perpassam o ensinar e o aprender conteúdos relacionados ao tema das DSTs. Este tema, comumente considerado como pertencente ao campo da saúde é abordado, sobretudo nas ações de prevenção em saúde muitas vezes centradas na transmissão de informações.

O período da adolescência tem sido objeto de atenção não só em relação aos cuidados que esta fase da vida requer, mas nas investigações em diferentes campos do saber, incluindo o da educação e da saúde. É caracterizado como um momento de transição, onde ocorrem desde mudanças de atitudes, questionamentos e formação de opiniões até a passagem à sexualidade com o parceiro (ALVES; BRANDÃO, 2009; CASTRO; ABRAMOVAY; SILVA, 2004; HEILBORN, 2003; 2006). Neste período, o corpo torna-se carregado de conotações que se revelam em objeto de obsessão da juventude, de elegância e de cuidados. No entanto, cada cultura exigirá do indivíduo diferentes atitudes ou responsabilidades durante a fase de adolescência e os acontecimentos que surgem podem ser interpretados de diferentes formas. (RODRIGUES, 2006). No campo das ciências humanas e sociais, o corpo tem sido objeto privilegiado de estudos antropológicos que apontam ser este interpretado de formas bastante específicas por sociedades e grupos sociais (MAUSS, 2003). Nesta perspectiva, entende-se que homem constrói socialmente o seu corpo a partir da interação com os outros onde produz qualidades que orientam suas significações e valores (LE BRETON, 2009).

Considerando a perspectiva das relações de gênero, o corpo sofre rápidas transformações, principalmente entre as meninas, e esse fator biológico também mexe com o imaginário das adolescentes e dos rapazes, exigindo a reconstrução de sua autoimagem e da sua identidade sexual (MANDÚ; CORRÊA, 2000; ALTAMANN, 2007). É a partir da adolescência que rapazes e moças começam a apresentar atitudes diferentes no que compete à sexualidade (BOZON, 2004). As trajetórias masculinas e femininas diferem, sobretudo em função da maneira como as expectativas e aspirações em relação à experimentação sexual são marcadas pelo gênero (HEILBORN, 2003; 2006), cujas representações também se dão no corpo e pelo corpo, em culturas específicas e de modos específicos.

De acordo com dados da literatura, a inscrição dos gêneros (masculino e feminino) nos corpos acontece contextualmente, em determinada cultura e com suas marcas. Assim, a construção do gênero e da sexualidade ocorre ao longo da vida, 
através de aprendizagens e práticas em diferentes instâncias sociais e culturais (LOURO, 2008; 2010). O gênero pode, portanto, ser compreendido como uma construção social, onde estão impressas normas, valores, percepções e representações que contribuem para a construção da identidade do sujeito (CARRADORE; RIBEIRO, 2004; TAQUETTE; VILHENA; PAULA, 2004). Segundo Scott (1995), “o gênero permite distinguir a prática sexual dos papéis sexuais atribuídos às mulheres e homens". Neste caso, é um elemento constitutivo de relações sociais baseadas em diferenças percebidas entre os sexos, ou seja, na percepção do que é ser homem e ser mulher.

A forma como adolescentes do sexo feminino e masculino manifestam suas dúvidas e desejos por informações a respeito de sexualidade, doenças, contracepção são diferenciadas. Perpassam por questões que abarcam o convívio familiar, a relação com os pares e as fontes de informação (BOZON; HEILBORN, 2006; HEILBORN, 2003). Enquanto as meninas dialogam, tiram dúvidas e confidencializam-se com a figura materna, os rapazes se identificam muitas vezes com os pais, algumas com a figura materna e com os seus pares, onde estes últimos exercem um papel relevante junto ao grupo de rapazes do que entre o grupo de meninas (BOZON; HEILBORN, 2006).

Como já assinalado, o tema das DSTs é considerado como um tema de saúde e sua abordagem encontra-se restrita na maioria das vezes à difusão de informações sobre transmissão e tratamento. Cabe, no entanto, destacar que o processo saúde-doença e a maneira como os sujeitos compreendem os eventos relacionados à saúde imbricam ao processo de socialização determinado pela cultura e que orienta as experiências e os comportamentos dos sujeitos (VICTORIA; KNAUTH; HASSEN, 2000). Não existem definições exatas para a relação saúde-doença ou ao que o indivíduo sente e vê como saúde e doença, ou seja, não tem um significado em si (RODRIGUES, 2005). Neste sentido, o significado que cada indivíduo traz para si a respeito do processo saúdedoença é de cunho histórico, social e cultural, características estas responsáveis pela concepção que cada indivíduo ou grupo social traz sobre sua situação. Pimenta e colaboradores (2007) apontam que as concepções de saúde e de doença estão associadas a fatores biológicos, sociais, econômicos, ambientais e culturais e que o "estado" de saúde pode estar relacionado ao modo de vida e seu universo social e cultural.

Tendo em vista a compreensão dos eventos associados ao ensino das doenças sexualmente transmissíveis no contexto escolar compreeendido como as relações que se estabelecem entre os diferentes atores envolvidos neste processo, este estudo apresenta, 
como parte de uma dissertação de mestrado $^{1}$, algumas reflexões acerca das diferenças de gênero entre jovens escolares presentes nas concepções que evolvem a sexualidade, tais como os cuidados relativos ao corpo bem como o entendimento do processo saúdedoença, as decisões e projeções que envolvem a iniciação sexual, as práticas preventivas e a escolha dos informantes pelos jovens. A compreensão destas questões é importante, na medida em que o tema das DSTs no contexto escolar perpassa as questões referentes aos conceitos biológicos abordados no ensino formal, além de constarem como tema transversal nos documentos oficiais, tornando-se relevante para o ensino $\mathrm{e}$ aprendizagem deste tema.

\section{METODOLOGIA}

$\mathrm{O}$ estudo corresponde a uma pesquisa qualitativa desenvolvido na perspectiva socioantropológica onde foram realizadas análises de documentos oficiais dos campos da saúde e da educação, incluindo o livro didático de biologia, observação direta do ensino formal e entrevistas com alunos de 17 a 20 anos e professores de biologia do ensino médio de uma escola estadual do Rio de Janeiro.

A análise documental que se conjugou aos dados do trabalho de campo focalizou as determinações dos Parâmetros Curriculares Nacionais (BRASIL, 1997; 1998), das Diretrizes Curriculares e das Propostas Pedagógicas da instituição de ensino participante do estudo correlacionadas às determinações oficiais do Departamento de DST/AIDS e Hepatites Virais (BRASIL, 2010), bem como o conteúdo de DSTs presente nas coleções didáticas de biologia aprovadas pelo MEC (BRASIL, 2004) ${ }^{2}$. Na reflexão aqui apresentada trazemos particularmente alguns aspectos presentes na percepção dos jovens escolares sobre sexualidade e prevenção de doenças, temáticas estas intrinsecamente relacionadas às DSTs e desenvolvidas no estudo mais amplo.

Os participantes do estudo foram comunicados quanto ao respeito aos seus direitos de recusa na participação da pesquisa, bem como a liberdade e sigilo em relação às suas respostas através de Termo de Consentimento aprovado por Comitê de Ética e Pesquisa $^{3}$.

\footnotetext{
${ }^{1}$ Dissertação de Mestrado Acadêmico: "Potencialidades e Limites do Ensino das Doenças Sexualmente Transmissíveis: um estudo qualitativo na perspectiva socioantropológica" em fase de conclusão.

${ }^{2}$ Parte dos resultados relacionados à análise das coleções didáticas de Biologia do PNLEM em uso no ano de desenvolvimento do estudo (2010) que abordam a temática das DSTs em livros didáticos está descrita no VIII ENPEC (Campinas, 5 a 9 dez 2011) sob o título: “As Doenças Sexualmente Transmissíveis em livros didáticos de biologia: aportes para o ensino de ciências", Anais do Encontro.

${ }^{3}$ A pesquisa foi submetida ao Comitê de Ética e Pesquisa e APROVADA tendo por referências as normas e diretrizes da Resolução 196/96 do Conselho Nacional de Saúde.
} 
Ensino, Saúde e Ambiente-V5 (2), pp. 258-269, ago. 2012

\section{RESULTADOS E DISCUSSÃO}

Quando o tema das DSTs foi abordado no espaço escolar, no contexto da pesquisa, observamos algumas questões que envolvem a sexualidade dos sujeitos que emergem a partir desta temática e que vão além do conteúdo biológico referenciado nos materiais didáticos, como se possa imaginar, tendo em vista o caráter complementar dos materiais na prática docente. Dentre elas está o posicionamento e concepções dos jovens acerca da iniciação sexual que traz questionamentos relativos às atitudes e cuidados voltados a este evento.

A priori, e de acordo com as recomendações das ações de prevenção de doenças, a primeira relação sexual deveria ser protegida e planejada. No entanto, pode ser observado nos discursos dos jovens que nem sempre isso acontece, sobretudo no que se refere à expressão de práticas diferenciadas entre moças e rapazes e entre os iniciados sexualmente ou em expectativas entre os não iniciados (BOZON; HEILBORN, 2006).

"Só depois da primeira que eu tomei mais cuidado.(...) Esqueci, por isso que eu falei, a gente não tem cabeça" (José, 17 anos, masculino).

"Eu penso em tudo, como usar, no que fazer, o que acontece na hora. Mas eu penso em tudo, principalmente nas doenças (...) Planejo sim, porque é uma coisa que você tem que tomar cuidado na hora de fazer pra não dar errado, pra não ter consequência lá na frente"(Andressa, 17 anos, feminino).

“... depois que a gente fizer exame e a gente não constatar nada, ai sim, sem exame não" (Geovanna, 17 anos, feminino).

Essa diversidade de expressões e práticas diferenciadas desses indivíduos quanto às medidas de prevenção podem estar relacionadas não somente ao conhecimento prévio relativo às doenças, mas também à compreensão de saúde e de doença e aos cuidados com o corpo, diferenciado por gênero, destes grupos.

Quando os alunos da pesquisa se expressaram com relação aos cuidados, pudemos observar algumas indicações de como compreendem os sintomas e primeiros sinais indicativos de DSTs e sobre o seu processo de identificação das doenças. Alguns alunos indicaram preocupações quanto às infecções por DSTs, a percepção dos sintomas mais comuns e dificuldades na identificação dos sinais corporais indicativos de DSTs. Reconhecer os sintomas para alguns alunos se reflete na possibilidade das doenças serem tratadas mais cedo. Segundo eles, o reconhecimento precoce é fundamental para o tratamento e cura da maioria das DSTs, embora reconheçam que para a AIDS, ainda não exista a cura. Essa percepção vai ao encontro do que é visto na literatura e nos nossos achados, em que a identificação precoce pode auxiliar em um tratamento mais eficaz. Outro ponto debatido, é que a identificação dos sintomas é tarefa fácil, contudo, 
relacioná-los à doença respectiva é um desafio, na medida em que existem sintomas comuns a mais de uma doença e são pouco explorados nas aulas destinadas à temática.

Neste contexto, julga-se importante o desenvolvimento de estratégias que conjuguem diversas fontes de informação (dos campos da educação e da saúde) para a identificação dos diferentes tipos de infecções sexuais e as formas de contaminação associadas à temática das DSTs pelos alunos, cujos dados demonstraram que eles obtêm um grau satisfatório de conhecimento a este respeito (CASTRO; ABRAMOVAY; SILVA, 2004; INSTITUTO DE SAÚDE, 2008).

Dentre as atitudes relativas às práticas sexuais, há aqueles que confirmam a adoção de medidas preventivas somente após a primeira relação sexual, aqueles que desde a primeira relação adotam o uso, e os que assumem a intenção de retirá-lo após exames laboratoriais. Há ainda aqueles que traduzem suas expectativas em discursos politicamente corretos reproduzindo as orientações médicas e educacionais dirigidas a este público. A iniciação sexual destes jovens, portanto, embora em um primeiro momento tenha se mostrado por vezes protegida ou planejada, nota-se a partir do que a jovem Geovanna relata, que o planejamento, que na concepção de Andressa permeava a primeira relação sexual protegida, no dela tende a se modificar ao longo do relacionamento, podendo ser abandonado o uso de preservativos. Ou seja, a relação de confiança estabelecida entre o casal na concepção de Geovanna é a questão fundamental para a adoção de medidas preventivas. De acordo com Oliveira e colaboradores (2009), muito jovens identificam que a prevenção é um elemento importante na prática sexual, entretanto, abdicam dela a partir do momento que sentem confiança no parceiro.

No que tange aos cuidados relativos do corpo, os jovens apresentam concepções distintas de gênero em seus discursos. Apontam um direcionamento de cuidado ao sexo feminino enquanto assinalam os homens como mais vulneráveis à contaminação por DSTs por suas atitudes comportamentais impregnadas na sociedade. Há também quem credite mais contaminação à menina por esta conceder o não uso do preservativo durante a relação sexual quando lhe fazem tal solicitação.

"Acho que os homens [pegam mais], porque vão na empolgação. A gente é mais cuidadosa, usa camisinha e eles não" (Suelen, 17 anos, feminino).

"Acho que o menino, homem é mais largadão, não gosta de usar essas coisas [camisinha], não gosta de se prevenir" (Rafael, 18 anos, masculino).

A percepção de que o comportamento masculino ou feminino se dá de diferentes formas pode estar inscrito nas concepções de grupos sociais e no significado 
dado às suas experiências. Estas definições classificatórias estão implícitas na cultura de dado grupo e acabam se refletindo no discurso e na imagem que o indivíduo faz de si e do outro (MAUSS, 2003; VICTORA; KNAUTH; HASSEN, 2000). Ao julgarem que meninos ou meninas se contaminam uns mais que os outros, acabam esquecendo de que as atitudes isoladas de qualquer um dos sexos trazem consequências para ambos, independente dos tipos de relações que estes estabeleçam com seus pares. Ainda neste contexto, existem aqueles que não expressam um posicionamento arraigado de gênero e assumem discursos que os equiparam no que compete a estas atitudes.

O comportamento definido para os grupos está também associado ao uso ou não de preservativo e consequentemente às atitudes relativas à prevenção. No que se reporta à prevenção das DSTs, existem diferenças de gênero nas concepções dos alunos.

"Os meninos se previnem mais. (...) Eu já tive uma experiência... a gente já era um tempo namorando, mas ele, a gente nunca tinha conversado sobre isso, mas ele que pegou a camisinha. Ai eu falei: Fulano, mas porque você quer usar? Quero porque previne e eu também não quero ser pai. Ele já estava com o pensamento do tipo: vou usar pô, não conheço, não sei se tem doença ou não. Eu não, eu já nem tava ai" (Tatiana, 18 anos, feminino).

O que chama a atenção na fala de Tatiana é o seu posicionamento quanto à propensão dos meninos a uma maior preocupação com a prevenção a despeito de seu relato acerca da atitude de um jovem que contraria sua percepção acerca das atitudes masculinas a este respeito. Tal depoimento indica a força das representações que se apresentam por vezes distanciadas das experiências vividas, bem como do conhecimento científico a eles dirigidos no processo de ensino e aprendizagem. Tais observações nos levam a crer que, algumas representações e experiências vividas ganham tamanho sentido para os jovens que estes acabam assumindo-as como verdades absolutas. Para Alves e Brandão (2009), práticas espontâneas e pouco reflexivas da sexualidade entre os jovens tende a reforçar os estereótipos de gênero e dificulta a adoção de medidas preventivas. Falas dos jovens do estudo ilustram este aspecto:

"Ah eu acho que os meninos não se preocupam, acham que na hora vai se satisfazer e não se preocupam se vai pegar doença ou se já está e vai passar pros outros, eles têm menos preocupação" (Regina, 17 anos, feminino).

"Acho que homem se previne menos, porque vai na questão do impulso. Tá ali na hora entendeu, às vezes esquece. Já aconteceu comigo uma vez com minha namorada. A mulher tá sempre ali: não e não sei o que, tem que usar camisinha, tem que tomar remédio. O homem age mais no impulso" (Jefferson, 18 anos, masculino). 
O aluno acima justifica sua postura com relação à adoção de práticas preventivas remetendo a uma incompatibilidade entre seus impulsos, como um atributo do gênero, e o necessário planejamento do uso do preservativo. A tendência neste tipo de percepção, portanto, é delegar esta função à mulher, que segundo o jovem é mais controlada e preocupada com estas questões. Essa visão colocada por Jefferson demonstra a existência de concepções distintas de sexualidade entre gêneros que modelam atitudes preventivas e de práticas sexuais. A construção do gênero e da sexualidade ocorre ao longo da vida a partir de aprendizagens e práticas em instâncias sociais e culturais (LOURO, 2008), imprimindo valores e percepções que contribuem para a construção da identidade do sujeito (CARRADORE; RIBEIRO, 2004; TAQUETTE; VILHENA; PAULA, 2004). Para Mauss (2003), os significados são construídos a partir das experiências de determinado grupo social. Os corpos ganham significado a partir da construção cultural dos sujeitos e é continuamente alterado por esta cultura, daí a inconstância atribuída ao corpo oriundo dos desejos e das necessidades que se julgam importantes (LOURO, 2010; LE BRETON, 2009).

Os diferentes posicionamentos de gênero também se inscrevem na forma como os meninos e meninas adolescentes obtêm suas informações sobre sexualidade, contracepção, gravidez e doenças sexualmente transmissíveis. Tais atitudes diferenciam-se entre si segundo o lugar atribuído à família, o grupo de pares ou fontes coletivas tais como os serviços de saúde, escolas, televisão, revistas e livros (BOZON; HEILBORN, 2006). As análises mostram além das diferenças quanto ao momento de busca por informações, as diferenças apontadas pelos adolescentes nos discursos sobre como obtêm suas informações e o diálogo com o parceiro e/ou seus informantes.

Entre os rapazes que já possuem um relacionamento, as reflexões e apontamentos sobre o diálogo com o parceiro, se fundamentam na percepção de cuidado e/ou de ensinar ao outro. Apesar de a (o) parceira (o) ser a pessoa fundamental nesta troca de informações, há quem afirme que os pais, irmãos e até amigos tem papel importante neste processo. Na adolescência, os jovens aos buscarem a socialização da sexualidade acabam dando importância ao seu grupo de pares, haja vista que eles creditam valor às interações sociais e às conversas sobre sexualidade que dividem com eles devido à proximidade de linguagem (FREIRE, 2005; VYGOTSKY, 2007; LOURO, 2010; TANATTO; SAPIRO, 2002).

"Converso com ela [namorada]. Acho importante, tem que... ela é mais nova do que eu entendeu, eu tenho mais experiência. (...) Ah, às vezes eu falo 
com a minha mãe, meu padrasto não. Com os amigos assim, também mais velhos e tal, mas no geral com minha mãe (...) Confio nela porque ela não vai querer me prejudicar" (Jefferson, 18 anos, masculino).

Dentre as meninas, o diálogo com o parceiro também ganha destaque na fala daquelas que já possuem um relacionamento. Contudo, mesmo estas, afirmam ter suas mães como informantes chaves com quem têm intimidade suficiente para conversar e tirar suas dúvidas. Entre as meninas entrevistadas que compõem o quadro de jovens não iniciadas sexualmente, o discurso quanto aos seus informantes é bastante parecido. Elas indicam a importância da conversa com o parceiro, através de outros informantes e fontes de informação além de indicarem como destaque a figura materna bem como a busca por profissionais médicos e professores.

"Busco conversar com meus pais, meu médico" (Graça, 17 anos, feminino).

"Tem que ter conversa. Quando a gente não tem experiência, a gente procura no livro, pergunta aos nossos pais. Vou e pergunto à minha mãe, eu converso mesmo" (Geovanna, 17 anos, feminino).

"Eu não tenho diálogo com meus pais sobre este tipo de assunto, então eu converso mais com minhas amigas. E eu busco em livros, revistas mais relacionado a isso, como se prevenir, como se cuidar. Quando eu estou com dúvida pergunto mesmo ao professor" (Andressa, 17 anos feminino).

Desta forma, os dados apontam que a figura materna ganha destaque como uma das principais fontes de informação das meninas, embora exerça papel importante na socialização dos meninos, sobretudo no que diz respeito à gravidez e à contracepção (BOZON; HEILBORN, 2006). Ainda sobre as diferenças de gênero entre meninos e meninas em pesquisa sobre as primeiras informações sobre relações sexuais, contracepção, gravidez e doenças sexualmente transmissíveis Bozon e Heilborn (2006) apontam que entre os entrevistados de ambos os sexos tenha eles tido relações sexuais ou não, raramente mencionam os médicos e serviços de saúde como fontes de informação, entretanto apontam a figura materna e a escola como principais fontes de informação no que se refere à gravidez e à contracepção. As informações sobre DST/AIDS ganham um caráter mais institucional e a escola e consequentemente os professores ganham papel relevante neste processo. Pouca referência é feita às obras didáticas ou programas voltados ao controle das DSTs. Tal fato pode ser entendido na medida em que as obras didáticas contemplam a temática das DSTs em sua maioria em tópicos de leitura complementar podendo ou não ser discutido no ambiente escolar ficando a cargo da escolha dos professores, creditam maior ênfase à AIDS em detrimento das demais doenças e não dão conta de aspectos subjetivos à sexualidade 
como observados no decorrer desta pesquisa que tendem a surgir a partir da discussão do tema em questão. Quanto aos programas voltados à temática, a reduzida repercussão entre os escolares poderia ser exemplificada pela ausência de propostas mais objetivas e atuantes no espaço escolar, bem como de informações mais fundamentadas, haja vista que apesar de compreender uma temática transversal, as DSTs são desenvolvidas estritamente com um enfoque biológico conteudista. Assim, as informações sobre estas questões ganham, portanto destaque através da figura materna e dos pares. Devemos, portanto, considerar que o diálogo com os pares e com pessoas a quem se credita confiança é decisivo para o aprendizado de questões relativas à sexualidade (FREIRE, 2005) e para o estabelecimento de uma interação entre as partes (VYGOTSKY, 2007).

\section{CONSIDERAÇÕES FINAIS}

De acordo com dados do estudo, o Ensino das DSTs envolve mais do que os conceitos científicos que permeiam os conteúdos da biologia associados à temática em tela, como observados no desenvolvimento deste estudo em diálogo com a literatura. Envolve a compreensão dos jovens sobre questões subjetivas à sexualidade e aspectos sociais e culturais presentes nas interações que configuram o ensino formal. Ou seja, a compreensão de aspectos sociais e subjetivos envolvidos na percepção dos estudantes no processo de aprendizagem da temática supracitada constitui em um aspecto relevante a ser considerado no ensino de ciências na medida em que estão presentes de modo significativo na aquisição do conhecimento científico relacionado ao tema.

As concepções dos sujeitos envolvidos e as percepções acerca das diferenças de gênero presentes nas tomadas de decisão em torno da iniciação sexual e as atitudes de prevenção das DSTs estão circunstanciadas não apenas por uma questão de acesso às informações ou ao conhecimento científico no contexto do ensino. Configuram estes eventos questões culturais, históricas e sociais que permeiam o espaço entre a informação recebida e a adoção de comportamentos sexuais relacionados à prevenção, bem a compreensão dos estados dinâmicos de saúde e de doença e dos cuidados com o corpo. Entender estes processos depende, portanto, de uma compreensão mais ampla acerca das relações entre saúde-doença e da construção do conhecimento científico junto aos indivíduos na relação de ensino-aprendizagem, pois estas estão relacionadas a fenômenos complexos que conjugam fatores biológicos, sociais, econômicos, ambientais e culturais a serem considerados.

A expressão da sexualidade centrada na experiência dos jovens se dá dentro de um contexto cultural trazendo consigo concepções distintas de gênero relacionados aos 
cuidados com o corpo e à compreensão dos estados dinâmicos de saúde e de doença. Neste sentido, é importante trabalharmos o tema das DSTs no contexto escolar e de ensino reconhecendo como estes aspectos culturais emergem a partir da análise dos temas abordados pelos professores junto aos alunos. Acreditamos deste modo poder contribuir para as discussões que enfatizam uma lacuna existente entre a construção do conhecimento biológico no contexto do ensino de ciências e as experiências e expectativas dos sujeitos. Por fim, apontamos como relevante a necessidade de se considerar os aspectos assinalados quando estivermos discutindo diferentes estratégias e possibilidades de abordagem do tema das DSTs nos contextos escolar e de ensino.

\section{REFERÊNCIAS BIBLIOGRÁFICAS}

ALTMANN, H. Educação sexual e primeira relação sexual: entre expectativas e prescrições. Estudos Feministas, Florianópolis, v.15, n.2 p. 333-356; 2007.

ALVES, C. M.; BRANDÃO, E. R. Vulnerabilidade no uso de métodos contraceptivos entre adolescentes e jovens: interseções entre políticas públicas e atenção à saúde.

Ciência \& Saúde Coletiva, Rio de Janeiro, vol. 14, n 2, , Mar/Abr, 2009. BOZON, M. Sociologia da Sexualidade. Rio de Janeiro. Editora FGV, 172p, 2004. . ; HEILBORN, M. L. Iniciação à sexualidade: modos de socialização,

interações de gênero e trajetórias individuais. In: HEILBORN, M.L.; AQUINO, E. M. L.; BOZON, M.; KNAUTH, D. R. (Orgs.). O Aprendizado da Sexualidade: reprodução e trajetórias sociais de jovens brasileiros. Rio de Janeiro: Garamond e Fiocruz, p.156-205, 2006.

BRASIL. Parâmetros Curriculares Nacionais: apresentação dos temas transversais/ Secretaria de Educação Fundamental. Brasília: MEC/SEF, 146p, 1997.

BRASIL. Parâmetros Curriculares Nacionais: Temas Transversais: Orientação Sexual. Ministério da Educação. Brasília: MEC/SEF, 436p, 1998.

BRASIL. Programa Nacional do Livro Didático para o ensino médio. PNLEM. Ministério da Educação, 2004. Disponível em www.fnde.gov.br acessado em 04 de outubro de 2009.

BRASIL. Programa Nacional de DST/AIDS. Ministério da Saúde. Disponível em www.aids.gov.br acessado em 17 de maio de 2010.

BRÊTAS, J.R.S.; SILVA, C. V. Orientação sexual para adolescentes: relato de experiência. Acta Paulista de Enfermagem. v.18 n.3, São Paulo, 2005.

CARRADORE, V. M.; RIBEIRO, P. R. M. Relações de Gênero, Sexualidade e AIDS: apontamentos para reflexão, 2004. Disponível em http://www.periodicos.udesc.br, acessado em 27 de julho de 2011.

CASTRO, M. G.; ABRAMOVAY, M.; SILVA, L. B. da. Juventude e sexualidade. Brasília: UNESCO, MEC, Coordenação Nacional de DST/AIDS, Secretaria Especial de Políticas para as Mulheres, Instituto Airton Sena, 2004.

FREIRE, P. Pedagogia do Oprimido, Paz e Terra, Rio de Janeiro, 2005.

HEILBORN, M. L. Articulando gênero, sexo e sexualidade: diferença na saúde. In:

GOLDENBERG, P.; MARSIGLIA, R. M. G.; GOMES, M. H. A. (Orgs.). O Clássico e o novo: tendências, objetos e abordagens em ciências e saúde. Fiocruz: Rio de Janeiro, p. 197-207, 2003.

. Experiência da Sexualidade, Reprodução e Trajetórias Biográficas Juvenis.

In:___ ; AQUINO, E. M. L.; BOZON, M.; KANUTH, D. R. (Orgs.). O 
Aprendizado da Sexualidade: reprodução e trajetórias sociais de jovens brasileiros. Rio de Janeiro. Garamond e Fiocruz, p. 29-59, 2006.

INSTITUTO DE SAÚDE. Comportamento Sexual, Uso de Preservativos e Contracepção de Emergência por Adolescentes do Município de São Paulo - estudo com estudantes de escolas públicas de Ensino Médio. FIGUEIREDO, R.; PUPO, L. R.; ALVES, M. C. G. P.; ESCUDER, M. M. L. (Orgs.) São Paulo: Instituto de Saúde, 38p, 2008.

LE BRETON, D. A Sociologia do corpo. $3^{\text {a }}$ edição. Editora Vozes, Petrópolis, Rio de Janeiro, 101p, 2009.

LOURO, G,L. Gênero e Sexualidade: pedagogias contemporâneas. Pró-posições, v. 19, n.2 (56), p.17-23, 2008.

LOURO, G. L. Pedagogias da sexualidade. In: LOURO, G. L. (Org.). O corpo

Educado: pedagogias da sexualidade. $3^{\text {a }}$ ed. Belo horizonte: Autêntica Editora, p.07-34, 2010.

MANDÚ, E. N. T.; CORRÊA, A. C. P. Educação Sexual Formal na Adolescência: Contribuições à Construção de Projetos Educativos. Acta. Paulista de Enfermagem. São Paulo, v.13, n.1, 27-37p, 2000.

MAUSS, M. As técnicas do corpo. In: Sociologia e antropologia. São Paulo: Cosac Naify, p. 339-422, 2003.

OLIVEIRA, D. C. de; PORTES, A. P. M. de; GOMES, A. M. T.; RIBEIRO, M. C. M. Conhecimentos e práticas de adolescentes acerca das DST/HIV/AIDS em duas escolas públicas municipais do Rio de Janeiro. Escola. Anna Nery, v.13, n. 4, p.833-841; 2009. PARKER, R. Cultura, economia política e construção social da sexualidade. In: LOURO, G. L. (Org.). O corpo educado: pedagogias da sexualidade. $3^{\text {a }}$ ed. Belo Horizonte: Autêntica Editora, p. 125-150, 2010.

PIMENTA, D. N.; LEANDRO, A.; SCHALL, V. T. A estética do grotesco e a produção audiovisual para a educação em saúde: segregação ou empatia? O caso das

leishmanioses no Brasil. Cadernos de Saúde Pública, Rio de Janeiro, v. 23, n 5; p.1161-1171, 2007.

RODRIGUES, J. C. "Os corpos e a Antropologia". In: MINAYO, M. C. S.;

COIMBRA, Jr. C. (Orgs). Críticas e atuantes: ciências sociais e humanas em saúde na América Latina. Editora Fiocruz: Rio de Janeiro; p.157-182; 2005.

RODRIGUES, J. C. Tabu do corpo. $7^{\mathrm{a}}$ Edição, Editora Fiocruz: Rio de Janeiro, 154p, 2006.

SCOTT, J. Gênero: uma categoria útil para a análise histórica. Educação e Realidade. Porto Alegre: Universidade Federal do Rio Grande do Sul; Faculdade de Educação, n. 20, n.2, p. 71-99, 1995.

TAQUETTE, S. R.; VILHENA, M. M. de; PAULA, M. C. de. Doenças Sexualmente Transmissíveis e gênero: um estudo transversal com adolescentes no Rio de Janeiro.

Cadernos de Saúde Pública, Rio de Janeiro, v.20, n.1, p.282-290, 2004.

TONATTO, S. E.; SAPIRO, C. M. Os novos parâmetros curriculares das escolas brasileiras e educação sexual: Uma proposta de intervenção em ciências. Psicologia e Sociedade, Porto Alegre, v.14, n. 2, p. 163-175, 2002.

VICTORA, C. G.; KNAUTH, D. R.; HASSEN, M. N. A. A Pesquisa qualitativa em saúde: uma introdução ao tema. Tomo Editorial: Porto Alegre, Cap.1, 2000. VYGOTSKY, L. S. A formação social da mente: o desenvolvimento dos processos psicológicos superiores. Implicações Educacionais. Capítulo 6. Martins Fontes, São Paulo, 2007. 